\title{
The relationship between depth and breadth of vocabulary knowledge and Iranian EFL learners' listening comprehension
}

\author{
Afshari, Sajad \\ University of Isfahan, Iran (afshari.sajad@yahoo.com) \\ Tavakoli, Mansoor \\ University of Isfahan, Iran (Mr.tavakoli14@gmail.gmail.com)
}

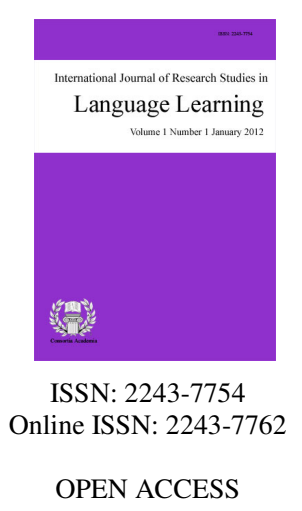

Received: 2 February 2016

Revised: 20 February 2016

Available Online: 15 May 2016

DOI: $10.5861 /$ ijrsll.2016.1438

Accepted: 27 March 2016

\begin{abstract}
This study investigates the relationship between depth and breadth of vocabulary knowledge and EFL learners' listening comprehension. It is designed to find out whether there is a meaningful relationship between vocabulary knowledge and listening comprehension in general, and to determine which dimension of vocabulary knowledge is a better predictor of successful listening comprehension in particular. Data gathered through three tests including Vocabulary Knowledge Test (VLT), Word Associate Test (WAT), and standardized listening comprehension test, from 32 EFL learners were analyzed and the findings revealed that there is a high and positive relationship among the three variables and also between the independent variables. Future analysis indicated that though both VLT and WAT contribute to listening comprehension, VLT is a better predictor of successful listening comprehension performance.
\end{abstract}

Keywords: vocabulary breadth; vocabulary depth; listening comprehension 


\section{The relationship between depth and breadth of vocabulary knowledge and Iranian EFL learners' listening comprehension}

\section{Introduction}

Language learners, teachers, and researchers agree that vocabulary is an essential element in the process of learning a language (Schmitt, 2008), because words are the primary conveyors of meaning (Vermeer, 2001) and thus carry the main information load in communication. As Wilkins (1972) states, "without grammar very little can be conveyed, without vocabulary nothing can be conveyed" (p. 111). While teachers and researchers have long recognized that "lexical competence is at the heart of communicative competence" (Meara, 1996, p. 35) and that vocabulary knowledge is a reliable predictor of learners 'proficiency' in a second or foreign language, research on vocabulary and language ability has almost exclusively focused on the skill of reading. Listening research has unfortunately depended to a great degree on findings borrowed from reading research, presumably because of the complexity in testing the oral modality. It is assumed that language comprehension is an ability which is relatively constant, regardless of perception modality (Lund, 1991). Although it has been shown that reading and listening skills are highly correlated in both L1 (Sticht, 1972; Jackson \& McClelland, 1979) and L2 (Hirai, 1999), research has revealed that there are some differences in comprehension performance between the two modalities among second language learners (Hirai, 1999; Lund, 1991).

There is no clear-cut answer to the question of how much lexis is necessary to listen to and comprehend texts in an L2. Kelly (1991) claimed that lexical ignorance is the major obstacle to listening comprehension among L2 learners. He concluded that adult L2 learners are highly unlikely to ever match native speakers in either bottom-up (speech perception) or top-down (discourse-level) listening processes, and suggested that their efforts would be better spent increasing their knowledge of the L2 (e.g., vocabulary and grammar), and especially their ability to recognize these words in their natural spoken style. To fully uncover the role of vocabulary knowledge in L2 proficiency, an empirical investigation of the extent to which vocabulary knowledge contributes to other language skills is needed.

This study is motivated by the fact that little research has investigated the effects of breadth and depth of vocabulary knowledge on learners' listening comprehension in EFL contexts in general and in Iranian EFL context in particular. To this end, this study was designed to determine the relationship between learners' vocabulary knowledge (depth and breadth) and their listening comprehension performance. The study was guided by the following questions:

$>$ RQ1: To what extent are breadth and depth of vocabulary knowledge associated with listening comprehension?

$>\quad$ RQ2: What is the relationship between breadth and depth of vocabulary knowledge?

$>$ RQ3: Which dimension of vocabulary knowledge - breadth or depth - is a better predictor of listening comprehension performance?

\section{Literature Review}

\subsection{Vocabulary knowledge}

At the theoretical level, the distinction of vocabulary knowledge may not be clear cut. A well-known framework for vocabulary knowledge was identified by Richards (1976) in terms of seven aspects. Later, Nation (1990) proposed eight types of word knowledge, specified both for receptive and productive knowledge. 
Chapelle (1998) suggested four dimensions for vocabulary knowledge. Henriksen (1999) distinguished three dimensions and Qian (2002) developed four dimensions from the earlier frameworks including vocabulary size, depth of vocabulary knowledge, lexical organization, and automaticity of receptive-productive knowledge. In spite of a lack of consensus as to the manner by which to capture the multidimensional nature of vocabulary knowledge, this distinction that the knowledge of vocabulary should comprise two basic dimensions, which are breadth or size and depth or quality, appears to be commonly accepted (Anderson \& Freebody, 1981; Qian, 1999, 2002; Read, 1993; Wesche \& Paribakht, 1996).

Breadth of vocabulary knowledge is described as the size of a learners' vocabulary. It is the number of words the learner has at least some significant knowledge of the meaning (Stæhr, 2009). Meara (1996) argued that vocabulary size is the basic dimension of a learner's lexical competence and emphasized that learners with large vocabularies are more proficient language users than learners with smaller vocabularies. Breadth or size tests provide basic measures of a learner's overall vocabulary knowledge, but they do not give clear indications of how well individual words are known. An estimate of overall vocabulary size can be obtained in two ways. The first one is based on sampling from a dictionary. This involves selecting a dictionary that contains the number or word families that learners are expected to know, then testing a selection of words. The problem of this method is that higher frequency words tend to have longer entries, and thus probably end up on the test, which may skew the results. Second, proficiency tests are based on corpus-derived lists of word families grouped by frequency. This method is used to estimate the vocabulary size by selecting word families regarding their frequency in a corpus. Commonly, these word families are grouped together in the first 1,000 most frequent words, the second 1,000 most frequent words, and so on. This can act as an indicator of the level of the learner's overall vocabulary knowledge based on sample words from frequency lists. This kind of test has generally been used only with people with low English vocabulary, namely non-native speakers of English (Nation, 1990).

Studies have shown that vocabulary size is directly related to the ability to use English in various ways. Knowledge of the most frequent 2000 words in English provides the bulk of the lexical resources required for basic everyday oral communication (Schonell, Meddleton, \& Shaw, 1956). The most frequent 3000 words provide materials for spoken discourse and this is also a threshold which should allow learners to begin to read authentic texts. The most frequent 5000 words provide enough vocabulary to enable learners to read authentic texts and allow them to infer the meaning of the many of the novel words from the context, and to understand most of the communicative context of the text. 10000 words allow for university study in the second language (Hazenburg \& Hulstijin, 1996). For L2 learners of English who are involved with an English-medium academic environment, knowledge of the sub-technical vocabulary that occurs across the range of academic disciplines is also necessary.

Depth of vocabulary knowledge refers to the quality of lexical knowledge that reflects how well words are organized in the learner's lexicon. In some studies, depth of vocabulary knowledge has been defined in relation to stages or degrees on a scale or continuum. Researchers who adopted this approach have essentially attempted to capture degrees of word knowledge with a primary focus on meaning through the use of vocabulary measures with varying degrees of sensitivity (e.g., Haastrup \& Henriksen, 1998; Joe, 1995) or through self-assessment scales (e.g., Wesche \& Paribakht, 1996). Another approach to the construct of depth offers a more extensive view of word knowledge by incorporating not only knowledge of semantic features but also of a wide range of other aspects of the word, such as its orthographic, phonological, morphological, syntactic, collocational, and pragmatic characteristics. Frameworks that specify multiple components of word knowledge (e.g., Nation, 1990, 2001) have then served as the theoretical underpinning for studies that address learners' depth of vocabulary knowledge (e.g., Schmitt, 1998, 1999; Schmitt \& Meara, 1997; Webb, 2005, 2007). A third approach to depth conceptualizes the construct as the degree to which words are integrated into the learner's mental lexicon and reflects the learner's ability to link the word to other related words. Learners' associative behavior is perceived as a reflection of their depth of vocabulary knowledge, and researchers have taken the degree of nativelikeness in learner responses in word association tests as an indication of depth. 
It seems that studies of word association have approached the construct of depth from two different perspectives: a word-oriented perspective that defines depth in relation to individual words (e.g., Haastrup \& Henriksen, 2000; Henriksen, 1999; Wolter, 2001) and a holistic, lexicon-oriented perspective that defines depth as a property of the lexicon as a whole (e.g., Meara, 1996a, 1996b; Meara \& Wolter, 2004; Read, 1993, 1998; Wilks \& Meara, 2002).

A widely adopted research tool used to investigate L2 learners' depth of vocabulary knowledge is Read's (1993, 1998) Word Associates Test (WAT). Although the format measures knowledge of individual words through a receptive word association task, it is essentially an attempt to assess learners' general qualitative knowledge of the lexicon in a practical fashion.

\subsection{Vocabulary knowledge and listening comprehension}

According to Nunan (1998, p. 1), "listening is the basic skill in language learning. Without listening skill, learners will never learn to communicate effectively. In fact over $50 \%$ of the time that students spend functioning in a foreign language will be devoted to listening". It is generally acknowledged that understanding aural text is an inferential process in which the listener actively constructs meaning through the employment of two major knowledge sources: linguistic (e.g., phonological, lexical, syntactic, semantic, or pragmatic knowledge) and nonlinguistic (e.g., knowledge of the context, topic, or general knowledge of the world) (Buck, 2001; Rost, 2002; Vandergrift, 2007). To make sense of spoken input, the listener applies a variety of the different types of knowledge through top-down and bottom-up processes, and it is assumed that successful listening comprehension is the result of a complex interaction between top-level and bottom-level cues. There is evidence to suggest that low-proficiency language learners with limited knowledge of the L2 favor a bottom-up approach in which they attempt to construct meaning by exclusively focusing on smaller units (e.g., lexical or syntactic) in the input (Conrad, 1985; Lynch, 1998; Rubin, 1994). On the other hand, more skilled listeners appear to make greater use of cognitive and metacognitive strategies; that is, they draw on top-level cues (Chamot, 2005; Vandergrift, 2003).

However, as Bonk (2000) emphasizes, top-level processing depends, to some degree, on the information obtained through bottom-level processing. If listeners have not recognized a certain number of words in the input though bottom-level processing, they will not be able to draw on top-level cues, access the relevant contextual information, and construct an adequate meaning representation of the text. Thus, word segmentation and recognition form the basis of spoken language comprehension (Rost, 2002). Nevertheless, knowledge of a word is no guarantee that the word will actually be recognized in continuous speech. Moreover, recognizing most of the words in the input does not guarantee comprehension, as many other factors also affect L2 listening comprehension. Some additional factors have been shown to be the following: first language (L1) listening ability (Vandergrift, 2006), text type (Shohamy \& Inbar, 1991), background knowledge and topic familiarity (Schmidt-Rinehardt, 1994), and purpose of listening (Shohamy \& Inbar, 1991). Meccarty (2000) found that the lack of grammatical knowledge and vocabulary, as well as word recognition skills may result in ineffective listening comprehension in L2 listeners.

Although the results from some studies emphasize that vocabulary knowledge is a determining factor for reading success, such findings simply cannot be transferred to listening; that is, it cannot be assumed that vocabulary knowledge plays an equally significant role and that identical vocabulary size or lexical coverage thresholds will apply to listening comprehension. There is no doubt that listening involves a set of skills in its own right (Lund, 1991) and that "listening is not merely an auditory version of reading" (Lynch \& Mendelsohn, 2002, p. 194). Although some of the same processes are believed to underlie reading and listening comprehension (Bejar, Douglas, Jamieson, Nissan, \& Turner, 2000) and although empirical studies have reported considerable degrees of similarity between reading and listening ability (Buck, 1992), the two skills are different in terms of both the linguistic characteristics of the input and the processing conditions. The notion that there is a difference between the role of vocabulary in reading and in listening is suggested by Mecartty (2000), who found 
The relationship between depth and breadth of vocabulary knowledge and EFL learners' listening comprehension

lexical knowledge to be more highly correlated with reading than with listening in a study of Spanish as an L2. Stæhr (2008) found that vocabulary size correlated more strongly with reading and writing abilities (0.83 and 0.73) than the skill of listening (0.69). A recent study by Mehrpour and Rahimi (2010) investigated the effects of both general and text-specific vocabulary knowledge on reading and listening comprehension. It appeared that learners' general vocabulary knowledge influenced their reading comprehension, but not their listening comprehension. In contrast, familiarity with text-specific vocabulary (tested by giving half of the participants a glossary with keyword definitions) had a significant effect on both reading and listening comprehension scores, but with a stronger effect on reading performance. However, only a few studies (Bonk, 2000; Kelly, 19913; Stæhr, 2007; Stæhr, 2009) have explicitly investigated the degree to which vocabulary knowledge is important for successful listening comprehension in EFL and whether there is a lexical threshold for adequate listening comprehension.

Stæhr (2007) investigated the relationship between vocabulary knowledge and listening comprehension and found a moderate association between a vocabulary size test (Vocabulary Levels Test; VLT) and a listening comprehension test (Cambridge Certificate of Proficiency in English). Regarding the number of words needed to understand the spoken discourse, Nation (2006) revealed that a vocabulary size of 6000 to 7000 word families is required in order to cover $98 \%$ of a text. Stæhr (2009) investigated the role of vocabulary knowledge in listening comprehension, with one hundred and fifteen advanced EFL learners in Denmark. The results revealed that the dimensions of breadth and depth of vocabulary knowledge measured by VLT and WAT were significantly correlated with listening comprehension measured by Cambridge certificate of proficiency in English, producing a coefficient of 0.70 and 0.65 respectively. Moreover, vocabulary knowledge could predict half of the variance in the listening scores. According to Stæhr (2009):

The review of the listening comprehension literature reveals two important facts. First, it demonstrates that the listening test should cover a variety of text types and topics and should, at a minimum, address the ability to (a) process samples of realistic spoken language, automatically and in real time; (b) understand linguistic information in the texts (e.g., specific words and phrases); (c) understand the gist of the texts; and (d) understand inferred meanings and nonstated implications in the texts. To some extent, this ability reflects what Buck (2001) defined as a default listening construct. Second, it is emphasized in the review of the listening comprehension literature that vocabulary knowledge is just one of several factors that contribute to successful listening comprehension. However, it is important to explore precisely how strong the association is between vocabulary knowledge and listening. Some studies (e.g., Bonk, 2000; Mecartty, 2000) have addressed this issue from different perspectives, but, in general, little research has been conducted on the role of vocabulary in listening (p. 583).

\section{Methodology}

\subsection{Participants}

The participants of the present study were 32 male EFL learners at high-intermediate and advanced levels of language proficiency in Khoy city, West Azerbaijan province, Iran. Some of the participants were high school students and some university students who attended language institutes in order to improve their overall language proficiency. Their age ranged between 16 and 26 years and they all shared Azeri Turkish as their first language.

\subsection{Instruments}

Three tests were used in this study including: Vocabulary Level Test, Word Associate Test, and a standardized TOEFL (Longman) listening comprehension test. 
Vocabulary Level Test - The VLT was originally produced by Nation in 1983 and it was later revised by him in 1990. The VLT used in this study was version 2 developed by Schmitt, Schmitt, \& Clapham, 2001. It provides an estimate of vocabulary size, composed of five separate sections, which represent four levels of word frequency and one level of academic words. In other words, this test measures learners' receptive knowledge of word meaning at these distinct vocabulary frequency levels: the 2,000 level, the 3,000 level, the 5,000 level, and the 10,000 level, as well as academic words from the Academic Word List (Coxhead, 2000). The 2000 and 3000 word-family levels test include only high frequency words in English; the 5000 word-family level is a boundary level between the high frequency and low frequency levels; and the 10000 word -family level includes low frequency words. The university word list level contains specialized vocabulary needed for academic studies.

It took 30 minutes to complete the test. The test scores provide and indicator of the number of words at each frequency level that the participants know. Each level in the test has 10 test items, each consisting of six words on the left and three definitions on the right. The participants were required to match the three definitions with three of the six words on the left. A sample test item is provided below.

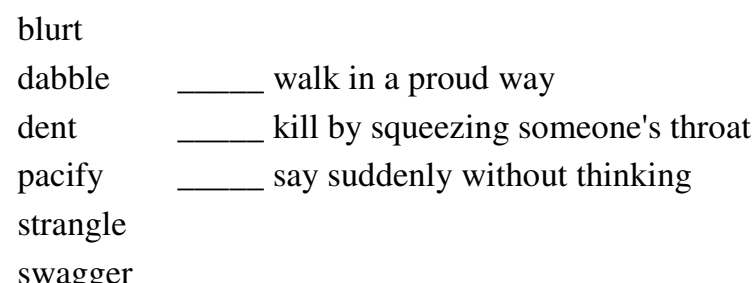

In scoring, each correctly chosen word received one point. The maximum possible score is 150 for the five levels, each of which consists of 30 items. The test results provide an indication of the proportion of the total number of words at each frequency level that the learner knows and can provide a profile of a learner's vocabulary. Based on Nation's scoring, the researchers assumed that a score of 20 out of 30 at each level could be an indication of that level's mastery.

Word Associate Test - WAT, developed by Read (1993), determines the depth of vocabulary knowledge through word associations, that is, the various semantic and collocational relationships that a word has with other words in the language. This version of the test consists of 40 items, each comprising a target word followed by a list of eight words, four of which are related to the target word whereas the other four are not. The test-takers are required to identify the four words related to the target word, so each item has four correct choices. An example is provided below.

ample

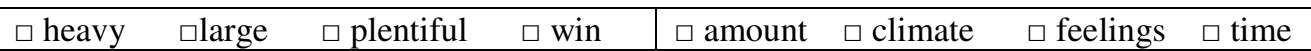

In the left box, one to three words (out of four) are synonyms of either the whole meaning of the target word (in this item, ample) or a component of its meaning; and in the right box, one to three words are collocates of the target word, often occurring together with the target word in a sentence. In this example, the correct answers on the left side are large and plentiful, and the correct answers on the right side are amount, and time with two correct answers in the left box and two correct answers in the right box. However, this may not always be the case and there are other alternatives. First, there may be one correct answer in the left box and three correct answers in the right box. Second, there may be three correct answers in the left box and one correct answer in the right box. This version of WAT is designed to measure two aspects of the depth of vocabulary knowledge: meaning and collocation. In scoring, test-takers received one point for each correctly chosen word. The maximum possible score is 160 as there are 40 items with four correct responses for each. The test took 35 minutes to complete.

Listening comprehension test - To assess the participants' listening comprehension a standardized test, that is, the listening section of one of the versions of the TOEFL Test (Longman) was used. The test consisted of 34 

multiple questions measuring the test-takers ability to understand conversations and lectures in English. There were two parts in the listening section. In each part the participants listened to one conversation and two lectures. They listened to each conversation and lecture only one time, but they were allowed to take notes while listening so that the results would not be affected by memory effect. After each conversation and lecture, the test-takers answered some multiple questions typically asking about the main ideas and supporting details. The first part of the test consisted of 17 questions, and the second part also consisted of 17 questions. Each correct answer received one point and the maximum point was 34 . The test took 50 minutes to complete.

\subsection{Procedures}

Data were collected in one session. First, the two tests measuring breadth and depth of vocabulary knowledge, that is, VLT and WAT were administrated consecutively (with a short break in between) to all participants. Then, the standardized listening comprehension test, i.e., TOEFL test, which addresses a wide range of skills involved in listening comprehension (e.g., listening for a gist, detail, stated and non-stated opinion, as well as making inferences) was given to assess the participants' overall listening comprehension. Before taking the tests, the participants were informed about the purpose of the study and were instructed on how to take the VLT and WAT tests. They were also assured of the confidentiality of the results.

\section{Data analysis}

In order to analyze the data, SPSS (Statistical Package for Social Sciences) was employed. The techniques used for statistical analyses were two-tailed Pearson product-moment correlations and multiple regressions. First, in order to find any possible correlation among the three variables (VLT, WAT, and listening comprehension), two tailed Pearson-product-moment correlations were conducted. Then, the participants' scores on VLT and WAT as independent variables and their scores on listening comprehension as a dependent variable were used to compute multiple regressions.

\section{Table 1}

Descriptive statistics for VLT, WAT, and listening comprehension tests

\begin{tabular}{lccccc}
\hline \multicolumn{1}{c}{ Variables } & $\mathrm{N}$ & Minimum & Maximum & Mean & SD \\
\hline VLT & 32 & 68.00 & 100.00 & 78.7812 & 9.67782 \\
WAT & 32 & 67.00 & 95.00 & 76.9063 & 8.87315 \\
Listening & 32 & 18.00 & 31.00 & 23.7500 & 3.54478 \\
\hline
\end{tabular}

As table 1 illustrates, the mean score of the VLT, WAT, and listening comprehension tests are 78.78, 76.90, and 23.75 respectively.

Second, in order to answer the first question of the study, that is, the relationship between vocabulary knowledge dimensions (breadth and depth of vocabulary knowledge) and listening comprehension, Pearson product-moment correlations were computed between the scores on vocabulary size and depth of vocabulary knowledge and the scores on listening comprehension. The results of these computations are presented in table 2.

\section{Table 2}

Pearson correlations between the vocabulary breadth (VLT), depth (WAT) and listening comprehension

\begin{tabular}{lccc}
\hline \multicolumn{1}{c}{ Variables } & VLT & WAT & Listening \\
\hline VLT & 1 & $.931^{* *}$ & $.852^{* *}$ \\
WAT & $.931^{* *}$ & 1 & $.833^{* *}$ \\
Listening & $.852^{* *}$ & $.833^{* *}$ & 1 \\
\hline
\end{tabular}

Note. ${ }^{* *}$ Correlation is significant at the 0.01 level (2-tailed)

Table 2 illustrates the correlations between the independent variables and the dependent variable and it also determines the strength of the association between them. The table reveals that the learners breadth of vocabulary knowledge (VLT) and their depth of vocabulary knowledge (WAT) are significantly correlated (.931, 
$p<.01$ ), indicating that these two independent variables are interrelated and that participants with larger vocabulary had also a deeper understanding and knowledge of words and vice versa. With regard to the relationship between the independent variable VLT and the dependent variable listening comprehension, it is evident that there is a significant correlation $(.852, p<.01)$ which means that the participants with larger vocabulary perform better in listening comprehension tasks. Finally, the correlation between the independent variable WAT and the dependent variable listening comprehension is also significant $(.833, p<.01)$. This is an indication of the fact that the participants' depth of vocabulary knowledge helps them to comprehend the listening task better.

To determine which of the independent variables, i.e., vocabulary size and depth of vocabulary knowledge, can explain the variance in the dependent variable, i.e., listening comprehension, a multiple regression analysis was conducted. The results are shown in table 3.

Table 3

Multiple regression for the relationship between reading comprehension and independent variables

\begin{tabular}{cccc}
\hline Model & R2 & F & Sig. \\
\hline 1 & .738 & 40.794 & .000 \\
\hline
\end{tabular}

It is evident from table 3 that the independent variables account for $73 \%$ of the variance in the dependent variable listening comprehension. However, we need to know the degree to which each of the independent variables is related to the dependent variable. Partial regression coefficient in table 4 demonstrates the unique contribution of each of the independent variables on the listening comprehension.

\section{Table 4}

Partial regression for the degree of prediction of independent variables on listening comprehension

\begin{tabular}{|c|c|c|c|}
\hline \multirow{2}{*}{ Model } & \multicolumn{2}{|c|}{ Unstandardized Coefficients } & \multirow{2}{*}{$\begin{array}{c}\text { Standardized Coefficients } \\
\text { Beta }\end{array}$} \\
\hline & B & Std. Error & \\
\hline VLT & .206 & .093 & .578 \\
\hline WAT & .115 & .101 & .295 \\
\hline
\end{tabular}

By looking at Beta indices in table 4, one can easily understand that VLT is stronger predictor of listening comprehension (.57). That is, $57 \%$ of the variance of the dependent variable is determined by the independent variable VLT. This means that, all the variables held constant, for every unit increase in the level of breadth of vocabulary knowledge, the listening comprehension score increased by .57 unit. On the other hand, the second independent variable WAT accounts for only 29 of variance of the listening comprehension, i.e., there was an increase in listening comprehension scores by .29 for every extra point in the level of vocabulary depth. This figure is considerably low compared to .57 of the VLT. Therefore, it can be concluded that the independent variable VLT is a better predictor of the listening comprehension scores than the independent variable WAT.

\section{Discussion}

The analysis of the data revealed that there is a positive relationship between vocabulary breadth and depth. This means that learners with larger vocabulary size have also deeper understanding of the words and that those with deeper understanding and knowledge of words have also larger vocabulary. Data analysis also revealed a positive correlation between the two independent variable (VLT \& WAT) and listening comprehension. This is in line with Stæhr (2009) who investigated the role of breadth and depth of vocabulary knowledge in listening comprehension and found that vocabulary breadth and depth were significantly correlated with listening comprehension producing a coefficient of 0.70 and 0.65 respectively and that vocabulary knowledge predicted half of the variance in the listening scores. This finding also lends support to Stæhr (2007) who found a substantial correlation (0.70) between a receptive vocabulary size test and a listening comprehension test (Cambridge Certificate of Proficiency in English) with 115 advanced EFL learners, suggesting that vocabulary 
size plays a crucial role in listening comprehension.

Further analysis of the findings in this study was that though both VLT and WAT contributed to the listening comprehension, compared to vocabulary depth, vocabulary breadth is a better predictor of listening comprehension performance. This finding lends support to the claims made by some researchers (e.g., Meara, 1996) that vocabulary size is the basic dimension of a learner's lexical competence and emphasized that learners with larger vocabularies are more proficient language users than learners with smaller vocabularies. These variables determine learners' listening comprehension.

\section{Conclusions and implications}

Though there is little research regarding the relationship between vocabulary knowledge and listening comprehension and most of the conclusions in this respect are drawn from the research on reading comprehension, the few studies conducted on the relationship between vocabulary knowledge and listening comprehension, including this study, point to the positive relationship between them and highlight the importance of focusing on teaching vocabulary as an important aspect of the linguistic competence. In this study, a positive relationship was found between the two independent variables (breadth and depth of vocabulary knowledge) and the dependent variable listening comprehension. As the findings revealed, there is a high and positive relationship between vocabulary breadth and listening comprehension meaning that learners with larger vocabulary size comprehend and perform better on the listening tasks compared to those with smaller vocabulary size. There was also a positive correlation between vocabulary depth and listening comprehension pointing to the fact that deeper understanding and knowledge of the words positively contributes to the successful listening performance. The fact that in this study the two independent variables, i.e., breadth and depth of vocabulary knowledge, are positively and highly correlated shows that teachers should take both of them into consideration in their vocabulary instruction. Since both dimensions of vocabulary knowledge positively contributed to the learners' listening comprehension, EFL teachers need to pay close attention to the development of their learners' vocabulary knowledge which enables them to perform more successfully in other language skills. This implies that EFL teachers need to consider these two dimensions as important aspects of the overall syllabus which help learners improve their listening comprehension. That is, in addition to introducing the basic meaning of the words, they should introduce synonyms and collocational relations of words with each other. Finally, with regard to the predictive power of the two dimensions of vocabulary knowledge, it was revealed that breadth of vocabulary knowledge is a better predictor of listening performance compared to the depth of vocabulary knowledge. Therefore, those learners who know more words perform better than those who have deeper understanding of the words in listening comprehension tasks. This finding indicates that language teachers should explicitly focus on expanding learners' vocabulary size in EFL classes. Overall, the findings of the present study can be beneficial for teachers and textbook writers to develop and design some activities which help learners to enhance both breadth and depth of their vocabulary knowledge.

\section{References}

Anderson, R. C., \& Freebody, P. (1981). Vocabulary knowledge. In J. T. Guthrie (Ed.), Comprehension and teaching: Research reviews (pp. 77-81). Newark, IRA.

Bejar, I., Douglas, D., Jamieson, J., Nissan, S., \& Turner, J. (2000). TOEFL 2000 listening framework (TOEFL monograph series, MS-19). Princeton, NJ: Educational Testing Service.

Bonk, W. (2000). Second language lexical knowledge and listening comprehension. International Journal of Listening, 14, 14-31. http://dx.doi.org/10.1080/10904018.2000.10499033

Buck, G. (2001). Assessing listening. New York: Cambridge University Press. http://dx.doi.org/10.1017/CBO9780511732959

Chamot, A. U. (2005). Language learning strategy instruction: Current issues and research. Annual Review of Applied Linguistics, 25, 98-111. http://dx.doi.org/10.1017/s0267190505000061

Chapelle, C. (1998). Construct definition and validity inquiry in SLA research. In L. F. Bachman \& A. D. Cohen 
Afshari, S., \& Tavakoli, M.

(Eds.), Interfaces between second language acquisition and language testing research (pp.32-70). Cambridge: Cambridge University Press.

Conrad, L. (1985). Semantic versus syntactic cues in listening comprehension. Studies in Second Language Acquisition, 7, 59-72. http://dx.doi.org/10.1017/S0272263100005155

Coxhead, A. (2000). A new academic word list. TESOL Quarterly, 34, 213-238. http://dx.doi.org/10.2307/3587951

CPE Handbook. (2002). Certificate of proficiency in English handbook: Specifications and sample papers for revised examination from December 2002. University of Cambridge Local Examinations Syndicate.

Haastrup, K., \& Henriksen, B. (1998). Vocabulary acquisition: From partial to precise understanding. In K. Haastrup \& A. Viberg (Eds.), Perspectives on lexical acquisition in a second language (pp. 97-124). Lund, Sweden: Lund University Press.

Haastrup, K., \& Henriksen, B. (2000). Vocabulary acquisition: Acquiring depth of knowledge through network building. International Journal of Applied Linguistics, 10, 221-240. http://dx.doi.org/10.1111/j.1473-4192.2000.tb00149.x

Hazenberg, S., \& Hulstijn, J.H. (1996). Defining a minimal second language vocabulary for non-native university students: An empirical investigation. Applied Linguistics, 17, 145-163. ttp://dx.doi.org/10.1093/applin/17.2.145

Henriksen, B. (1999). Three dimensions of vocabulary development. Studies in Second Language Acquisition, 21, 303-317. http://dx.doi.org/10.1017/s0272263199002089

Hirai, A. (1999). The relationship between listening and reading rates of Japanese EFL learners. The Modern Language Journal, 83(3), 367-384. http://dx.doi.org/10.1111/0026-7902.00028

Joe, A. (1995). Text-based tasks and incidental vocabulary learning. Second Language Research, 11, 149-158. http://dx.doi.org/10.1177/026765839501100206

Kelly, P. (1991). Lexical ignorance: The main obstacle to listening comprehension with advanced foreign language learners. International Review of Applied Linguistics, 29, 135-149.

Lund, R. (1991). A comparison of second language listening and reading comprehension. Modern Language Journal, 75, 196-204. http://dx.doi.org/10.1111/j.1540-4781.1991.tb05350.x

Lynch, T. (1998). Theoretical perspectives on listening. Annual Review of Applied Linguistics, 18, 3-19. http://dx.doi.org/10.1017/S0267190500003457

Lynch, T., \& Mendelsohn, D. (2002). Listening. In N. Schmitt (Ed.), An introduction to applied linguistics (pp. 193-210). London: Arnold.

Meara, P. (1996 a). The dimensions of lexical competence. In G. Brown, K. Malmkjær, \& J. Williams (Eds.), Performance and competence in second language acquisition (pp. 35-53). New York: Cambridge University Press.

Meara, P. (1996 b). The vocabulary knowledge framework. Retrieved from http://www.lognostics.co.uk/vlibrary/meara1996c.pdf

Meara, P., \& Wolter, B. (2004). V links: Beyond vocabulary depth. Angles on the English Speaking World, 4, $129-140$.

Mecartty, F. (2000). Lexical and grammatical knowledge in reading and listening comprehension by foreign language learners of Spanish. Applied Language Learning, 11, 323-348.

Nation, I. S. P. (1990). Teaching and learning vocabulary. New York: Newbury House.

Nation, I. S. P. (2001). Learning vocabulary in another language. New York: Cambridge University Press. http://dx.doi.org/10.1017/CBO9781139524759

Nation, I. S. P. (2006). How large a vocabulary is needed for reading and listening? Modern Canadian Language Review, 63, 59-82. http://dx.doi.org/10.3138/cmlr.63.1.59

Nunan, D., 1998. Approaches to teaching listening in the language classroom. In Proceedings of the 1997 Korea TESOL Conference. Korea TESOL, Taejeon, Korea, pp. 1-10.

Qian, D. (1999). Assessing the roles of depth and breadth of vocabulary knowledge in reading comprehension. The Canadian Modern Language Review, 56, 282-308. http://dx.doi.org/10.3138/cmlr.56.2.282

Qian, D. (2002). Investigating the relationship between vocabulary knowledge and academic reading 
The relationship between depth and breadth of vocabulary knowledge and EFL learners' listening comprehension

performance: An assessment perspective. Language Learning, 52, 513-536. http://dx.doi.org/10.1111/1467-9922.00193

Read, J. (1993). The Development of a new measure of L2 vocabulary knowledge. Language Testing, 10(3), 355-371. http://dx.doi.org/10.1177/026553229301000308

Read, J. (1998). Validating a test to measure depth of vocabulary knowledge. In A. Kunnan (Ed.), Validation in language assessment (pp. 41-60). Mahwah, NJ: Erlbaum.

Richards, J. (1976). The role of vocabulary teaching. TESOL Quarterly, 10(1), 77-90. http://dx.doi.org/10.2307/3585941

Rost, M. (2002). Teaching and researching listening. London: Longman.

Rubin, J. (1994). A review of second language listening comprehension research. Modern Language Journal, 78, 199-221. http://dx.doi.org/10.1111/j.1540-4781.1994.tb02034.x

Schmidt-Rinehart, B. (1994). The effect of topic familiarity on second language listening comprehension. Modern Language Journal, 78, 179-189. http://dx.doi.org/10.1111/j.1540-4781.1994.tb02030.x

Schmitt, N. (1998). Tracking the incremental acquisition of second language vocabulary: A longitudinal study. Language Learning, 48, 281-317. http://dx.doi.org/10.1111/1467-9922.00042

Schmitt, N. (1999). The relationship between TOEFL vocabulary items and meaning, association, collocation and word-class knowledge. Language Testing, 16, 189-216.

Schmitt, N. (2008). Instructed second language vocabulary learning. Language Teaching Research, 12, 329-363. http://dx.doi.org/10.1177/1362168808089921

Schmitt, N., \& Meara, P. (1997). Researching vocabulary through a word knowledge frame-work: Word associations and verbal suffixes. Studies in Second Language Acquisition, 19, 17-37. http://dx.doi.org/10.1017/S0272263197001022

Schmitt, N., Schmitt, D., \& Clapham, C. (2001). Developing and exploring the behaviour of two new versions of the vocabulary levels test. Language Testing, 18(1), 55-89.

Schonell, F. J., Meddleton, I. G., \& Shaw, B. A. (1956). A study of the oral vocabulary of adults. Brisbane, Australia: University of Queensland Press.

Shohamy, E., \& Inbar, O. (1991). Validation of listening comprehension tests: The effects of text and question type. Language Testing, 8, 23-40. http://dx.doi.org/10.1177/026553229100800103

Stæhr, L. S. (2007). The relationship between vocabulary knowledge and listening comprehension in English as a foreign language. Copenhagen Business School.

Stæhr, L. S. (2009). Vocabulary knowledge and advanced listening comprehension in English as a foreign language. Studies in Second Language Acquisition, 31(4), 577-607. http://dx.doi.org/10.1017/S0272263109990039

Vandergrift, L. (2003a). From prediction through reflection: Guiding the students through the process of L2 listening. Canadian Modern Language Review, 59, 425-440. http://dx.doi.org/10.3138/cmlr.59.3.425

Vandergrift, L. (2003b). Orchestrating strategy use: Toward a model of the skilled second language listener. Language Learning, 53, 463-496. http://dx.doi.org/10.1111/1467-9922.00232

Vandergrift, L. (2006). Second language listening: Listening ability or language proficiency? Modern Language Journal, 90, 6-18. http://dx.doi.org/10.1111/j.1540-4781.2006.00381.x

Vandergrift, L. (2007). Recent developments in second and foreign language listening comprehension research. Language Teaching, 40, 191-210. http://dx.doi.org/10.1017/S0261444807004338

Vermeer, A. (2001). Breadth and depth of vocabulary in relation to L1/L2 acquisition and frequency of input. Applied Psycholinguistics, 22, 217-235. http://dx.doi.org/10.1017/S0142716401002041

Webb, S. (2005). Receptive and productive vocabulary learning: The effects of reading and writing on word knowledge. Studies in Second Language Acquisition, 27, 33-52. http://dx.doi.org/10.1017/s0272263105050023

Webb, S. (2007). The effects of repetition on vocabulary knowledge. Applied Linguistics, 28, 46-65. http://dx.doi.org/10.1093/applin/am1048

Wesche, M., \& Paribakht, T. S. (1996). Assessing second language vocabulary knowledge: depth versus breadth. Canadian Modern Language Review, 53, 13-40. 
Afshari, S., \& Tavakoli, M.

Wilkins, D. A. (1972). Linguistics in language teaching. London: Edward Arnold.

Wilks, C., \& Meara, P. (2002). Untangling word webs: Graph theory and the notion of density in second language word association networks. Second Language Research, 18, 303-324.

http://dx.doi.org/10.1191/0267658302sr203oa

Wolter, B. (2001). Comparing the L1 and the L2 mental lexicon. Studies in Second Language Acquisition, 23, 41- 69. http://dx.doi.org/10.1017/S0272263101001024 